\title{
Social Support and Adolescents' Alcohol Use: An Integrative Literature Review
}

\author{
Ayman M. Hamdan-Mansour \\ Psychiatric Mental Health Nursing Department, Community Health Nursing School of Nursing, The University of Jordan, \\ Amman, Jordan \\ Email: a.mansour@ju.edu.jo, aymanjabay@gmail.com
}

How to cite this paper: Hamdan-Mansour, A.M. (2016) Social Support and Adolescents' Alcohol Use: An Integrative Literature Review. Health, 8, 1166-1177. http://dx.doi.org/10.4236/health.2016.812120

Received: August 8, 2016

Accepted: August 30, 2016

Published: September 2, 2016

Copyright $\odot 2016$ by author and Scientific Research Publishing Inc. This work is licensed under the Creative Commons Attribution International License (CC BY 4.0).

http://creativecommons.org/licenses/by/4.0/ (c) (i) Open Access

\begin{abstract}
The trajectories at treatment of alcohol use and abuse among adolescents have become a major health concern. The purpose of this paper was to discuss alcohol use and abuse among adolescents and its relationship to social support. Integrative review has been utilized to address the issue. There is a presentation of findings from research examining social support concepts and their relationship to adolescents' alcohol use and abuse. Treatment requires awareness of underlying causes in order to establish effective treatment approaches. Determining these underlying causes requires adequate knowledge of family, peers, and societal influences on adolescents' alcohol use and abuse. Health professionals across disciplines have an important role in implementing multidisciplinary interventions. The purpose of this paper was to discuss alcohol use and abuse among adolescents and its relationship to social support. Results, controversies and concerns raised by the reported results are addressed. Implications for future research are delineated.
\end{abstract}

\section{Keywords}

Adolescents, Alcohol Abuse, Social Support, Peer Pressure, Family Support

\section{Introduction}

Substance and violence seem to overwhelm modern societies, and nowadays, has become one main issue that concerns health care professionals at the developing countries. Substance related problems are reported to be common among youth, and research concerning substance use indicates that youth experiments substance use early in their adolescence [1]. Considerable efforts have been expended to determine the risk factors and predictors of adolescents' substance use. During the early adolescence pe- 
riod, behaviors and attitudes toward substance use are developed and acquired [2]. Adolescents, who are mainly at the age of (11 to 21 years), are vulnerable to life-long risk behaviors that contribute substance and aggressive behaviors [3]. In Jordan, 13\% of university students reported smoking tobacco, and positive correlation found between substance abuse problems and suicidal ideation, troubles with laws and university, troubles with sexual potency, and parent use of drug/alcohol [4]. The effects of substance use and abuse on young people are staggering in terms of substance dependence, injury, illegal acts, poor academic performance, risky sexual behaviors, and high costs to the surrounding community [5]. The purpose of this paper was to discuss alcohol use and abuse among adolescents and its relationship to social support. There is a presentation of findings from research examining social support concepts and their relationship to adolescents' alcohol use and abuse.

\section{Methods}

\subsection{Data Source}

The article search was conducted by the first author. EB identified articles by scanning and reviewing all existing literature reviews of adolescent substance use and abuse. Reference lists of these articles were further reviewed for relevant studies. Then a literature searches were conducted between January 2000 to December 2015 using the online databases: Medline/Pubmed, PsycINFO, Google Scholar, British Nursing Index, ProQuest, Elsevier, EBSCOhost, and Cumulative Index to Nursing and Allied Health Literature (CINAHL) Plus using the following search keywords: adolescent, teen, substance use, tobacco, smoking, alcohol, drugs, social support, peer pressure, family support, and community support. Only peer-reviewed papers published in Arabic and English were considered; no geographical limits were used.

Medical subject headings ( $\mathrm{MeSH}$ ) descriptors or appropriate permutations were used to index the content of the databases. The Boolean operators "AND" and "OR" were used as connectors to combine the various search terms and help narrow down the search. Using "AND" ensures that articles with both search terms are retrieved whereas using "OR" ensures the retrieval of articles with either of the search terms. Care was taken to increase specificity and sensitivity of the searches, using the search terms that were deemed most appropriate to ensure the identification of all potentially relevant articles. With the aid of these Boolean operators, the search terms were combined as follows: alcohol use AND social support OR peer support OR family support; alcohol abuse AND social support OR peer support OR family support; and alcohol use AND community support OR peer support OR family support (Table 1).

Table 1. Boolean table showing keywords used for research.

\begin{tabular}{ccccc}
\hline \multicolumn{5}{c}{ List of search terms: } \\
\hline Alcohol use & AND & Social support & OR & Peer support \\
Alcohol use & AND & Social support & OR & Family support \\
\hline
\end{tabular}




\subsection{Inclusion and Exclusion Criteria}

Scoping searches retrieved a considerable number of relevant articles, thus justifying the research question. The inclusion criteria included articles published in the English and Arabic language, research studies specifically related to alcohol use and abuse, studies conducted on adolescents, and relevant publications regardless of the study design. The inclusion criteria also included articles published from the year 2000 to 2015 to ensure that only current evidence is explored. The exclusion criteria included studies that were not relevant to alcohol use and abuse, studies published in languages other than English and Arabic, and studies with publication older than 2000 (Table 2).

\subsection{Alcohol Use and Abuse among Adolescents}

Adolescence is that stage of life between childhood and adulthood or between early puberty to the early 20 's. Although there is no definite age when adolescents become adults, the adult should have financial independence, employment, and marriage [6]. Adolescence is also characterized by a high capability for initiating life-long risk behaviors. Various theories were developed to explain adolescents' alcohol abuse. This increasingly concern was due to results found in adult alcohol studies. The young adults' alcohol studies revealed that alcohol abuse is associated with numerous health problems, impaired social functioning, occupational performance and competence [7]. Demographic factors such as age, gender, race, and geographical location have also associated with significant difference among adult's alcohol abuse and dependence [8]. These findings motivated researchers to look at the adolescence stage as one of the main life stages that predict individual's health behaviors during the adulthood. This is terms of lack of awareness of sources of knowledge and inability to utilize the telecommunication sources of knowledge in general [9].

The literature on adolescents' alcohol problems showed that alcohol problem is rarely detected in adolescents alone, and almost accompanies a list of risky behaviors [10]. Adolescents' alcohol problem are associated with poor school performance, juvenile delinquency, sexual promiscuity, impaired driving, family problem, and mental health problems including suicide and depression [4] [11].

\subsection{Social Support and Adolescents' Alcohol Problem}

\section{Concepts of Social Support}

Table 2. Summary of literature research.

\begin{tabular}{lll}
\hline Databases Searched & Inclusion Criteria & Exclusion Criteria \\
\hline - Medline/Pubmed & - Publications in English and & - Publications in languages \\
- PsycINFO & Arabic languages & other than English and \\
- Google Scholar & - Published 2000-2015 & Arabic \\
- British Nursing Index & - Relevance to the study question & - Publications older than 2000 \\
- ProQuest & - Any study design & Editorials and commentaries \\
- Elsevier & & \\
- EBSCOhost & & \\
- (CINAHL) Plus & & \\
\hline
\end{tabular}


Great advances have been made in social support research since Durkheim (1951). Definitions and analysis of social support attributes has been moderately studied due to the complexity of social support concept [12]. Social support, for some researchers refers to as a process [12], while others look at social support as a buffer to stress and means of coping [10]. Social support is also seen as a metaconstruct encompassing numerous features of social relationships. Cohen and his colleagues [12] defined social support as the process "through which the social relationships promote health and well-being." (p. 4). Social relationship, however, may be at one time a source of intima$\mathrm{cy}$, guidance and assistance, and at other times a source of conflict and loss. Social support, according to Barrera [13], can be organized in three major categories: social embeddedness, perceived social support, and enacted support. Social embeddedness is "the connections that individuals have to significant others in their social environment" [13]. Social embeddedness is the presence of social ties and involvement in community and organization, or individuals' social network analysis. Perceived social support refers to the "cognitive appraisal of being reliably connected to others" [13]. Perceived social support is the most studied social support concept in the literature and is measured by examining the perception of availability and adequacy of social ties. The latter category is enacted support which refers to the individual's actions and interactions that the individual uses to overcome and adjust with resistance in his social relationships with significant others. This category reflects what people do to cope with resistance and to maintain their social ties [14]. Within these categories, all the social relationships, interactions, networking, ties, involvement, and processes take place. Within certain limits the concepts of social embeddedness, perceived social support, and enacted support can be used interchangeably.

\subsection{Relationship among Family, Peer, School, and Community}

As mentioned above, the adolescence is a transitional phase between childhood and adulthood. During this period, the adolescent assumes behavioral roles, engages in interpersonal relationships, and participates in activities. All social activities take place within family, peer, school, and neighborhood arenas that are considered the primary source of adolescents' socialization [7]. The ecological area influences the adolescent's behavior relative to that of family influence. For example, child maltreatment reflects poor social networking in the community regardless of socioeconomic status [15]. Ecological factors are strongly associated with involvement in gang activities [15]. During adolescents' interactions with the microsystems they develop perceptions of being cared of, valued, and supported in his relationships. On the other hand, adolescent may have a perception of being rejected and unsupported. Bandura's [15] social learning theory maintained that child goes through different developmental stages where he builds social relationships through social interactions and through which he views and imitates role models. Models are possibly family member, friend, and can be found in the society. This builds on the adolescent's perception and affects his attitudes and behaviors. Therefore, the parental model and peer model are very likely to have an impact on the adolescent's behavior, perceptions, and attitudes. 


\subsection{Social Support and Health}

The observed influence of social relationships on the health of individuals and society has evoked the attention of scientists from different disciplines. Despite the established relationships between social relationships and person's health, the relationship seems to be complex and the mechanism by which this relationship occurs is not well understood [12]. The link between social support and health was established by Durkheim [16] who addressed the association between social aggregation and psychological well-being. Social support is a function of social aggregation where the person can function and build relationships [17]. Later studies confirmed this linkage, as researchers found that mental health is more often observed in large societies rather than in smaller, closed ones. Social support was found to buffer stress, affect the person's perception of self-esteem and reinforce intimacy and dependability [18]. Moreover, social support affects the risks for physical illness by influencing the individual's behaviors in a variety of daily living activities, traditions, and health practices.

According to Cohen, Gottlieb and Underwood [12], social support influences health through either the stress-buffering model or the main effect model. The main premises of the stress-buffering model is that others will provide necessary resources that may redefine the potential for harm posed by a situation and cushions one's perceived ability to cope with imposed demands, thereby preventing a particular situation from being perceived as stressful. Supportive beliefs may reduce maladaptive behaviors. The maineffect model claims that the individual is under the influence of social control and peer pressure [12]. These two models provide an explanation for how an individual's physical and mental health is maintained and promoted. The individual's social support, based on the stress buffering and main effect models, influences the individual's emotions, cognition, and behaviors. Consequently, individuals are able to perceive risk factors and functions in a healthy way to maintain and promote their health.

Social support is viewed as a protective factor in adolescence [19] and has a significant role in the adolescent's interpersonal relationships. Researchers have found that social support is inversely related to depression among young adults [20]. Adolescents who reported less received social support from friends and family were found to be emotionally less positive adults [20]. Further, social support has been found to mediate stress and anger among adolescents [7]. Gender also influences reasons for seeking social support. Girls, more than boys, seek social support for moral reasons, while boys seek support from friends known to support aggressive behaviors [21].

Early research on social support focused on its positive features with little attention to the negative ones. Social support is primarily measured as perceived or received social support or what so called a functional support. However, the findings are controversial. While some research provides positive associations between received social support and symptomatology, other findings reveal negative associations [12].

\subsection{Influence of Peer and Family on Adolescents' Alcohol Problem}

Families and peers have also been recognized as a good means of predicting adolescents 
who are more likely using or abusing alcohol. The studies on social support and alcoholism revealed that adolescent's susceptibility to use alcohol and other drugs is related to the level of attachment with family and peers [22]. Adolescents who reported stronger relationships with their families use alcohol less than their counterparts who reported more problems with their families. Paternal monitoring of adolescents' behaviors has been inversely associated with drug and alcohol use [23]. An important factor in adolescents' alcohol problems is the family history of alcohol problems. Paternal alcohol abuse has been significantly associated with dysfunctional coping models and problematic social interaction among adolescents [22]; therefore, the father who is alcoholic mainly affects adolescents during the period of development where they need to establish and practice social skills. Consequently, the adolescents in that stage will most likely have impairment in their social relations inside and outside home. This leads adolescents to a state of social confusion. Adolescents who lack the involvement and closeness with their families turn to peers for intimacy. Strasburger [24] found that strong engagement with parental relationship was a good indicator of healthy behaviors over time; however, strong engagement with peers was found to be more related to adolescents' substance abuse [24].

Parental alcohol abuse was found to be less effective than the attitudes of peers toward alcohol use in relation to adolescent's behavior. Peer approval of alcohol use was found to have a stronger relationship with alcohol and drug abuse among adolescents. The effects of peer and family on the adolescents' alcohol use are different depending on the gender of adolescent [25]. For girls, family characteristics and closeness is the best predictor for alcohol abuse. For boys, peers have the stronger influence toward use and abuse of alcohol. Peers within the same school establish peer norms that are transmitted from one to another [18]. Adolescents in the same school develop alcohol and other substance abuse through social interaction. For older adolescents the substances are used to reduce tension and anxiety that results from psychosocial distresses. Children who are peer oriented rather than family oriented is more likely to develop alcohol and drug abuse and conduct behaviors.

Contrary to these studies, Piko [23] found that neither mother nor friend perceived social support was a predictor of substance use. However, father perceived social support was a significant predictor of all types of substance use [4]. The impact of adolescents' perceived father social support on substance use may be explained due to the effects of the intimate relationship with the father on the adolescents' social image and personal identity. Social image and personal identity are major components of self-esteem that have found to be significantly related to alcohol and drug abuse. Piko [23] also found that school type, age, and gender were strong predictors of substance use among adolescents. Males were more often than females and older more often than younger adolescents were found to use substances. It is clear from the present review that both family and friends have a significant effect on the adolescent's alcohol use and abuse. Peers more than family affect the adolescents' alcohol problem. Although family support has more influence on the adolescents' health behaviors, peer support and attitudes toward alcohol use have a stronger impact on adolescents' alcohol use and abuse. 


\subsection{Impact of Media on Adolescents' Alcohol Use and Abuse}

Social availability refers to media advertisement. Concerns from parents, professionals and society have been increasingly noted regarding the effects of media on adolescent's behaviors and attitudes. In the last few years, incidents and murders in schools provoked questions related to the growing violence and behavioral problems among adolescents. Concerns emphasized role of media exposure and called for diagnosis and treatment of the problem [24]. Alcohol was one of the main issues addressed due to the considerable amount of alcohol advertisement in television shows, movies, and music videos [24]. Adolescents are heavy users of television, and television has been recognized as a powerful socializing factor for adolescents and is considered as a leading source of information about alcohol for adolescents [24].

Due to the complexity of the problem, in which rules and regulation prohibit alcohol use among individuals under 21, very few studies addressed the effects of physical, economic, and social availability on adolescents alcohol use. Among the few studies, Johnston and Colleagues reported that the number of youth (17-21 years old) beer drinkers was negatively associated with the price of beer and the state's legal minimum age for beer. In another study, Hussong [26] found that the number of youth beer drinkers who drink beer at least once each week is negatively affected by the price and the state's legal minimum age of beer. Children who demonstrated more knowledge of beer brands and slogans have more favorable beliefs about drinking, and more frequently intended to drink as adults [26]. The results have been supported by other studies that have linked hostility, psychological wellbeing to substance use [27]-[30]. The study revealed that the amount of beer consumed at the age of 21 was related significantly to the amount of beer consumed at age of 18, the liking of the alcohol advertisement, and brand allegiance. They also found that gender was a significant variable. Males more than females liked the advertisement and consumed more beer [31] who found a positive relationship between liking to alcohol advertisement and increase in alcohol use.

\section{Discussion}

The predominant theme of the reviewed literature on social support and alcoholism among adolescents suggests that social support has a positive effect on the adolescents' alcohol use and abuse. However, measuring social support is an essential element in predicting relationships and associations. Social support is a broad concept that refers to processes through which many social processes and interactions seen. The moderate correlation between social support concepts requires researchers' attention to the scales and measures that they use [32]. The reviewed studies recognize the complexity and variability of social support concept. This variability requires attention when selecting the conceptual model and concepts under which social support is defined and operationalized.

The findings of the reviewed studies, generally, support the peer pressure as a pre- 
dictor of adolescents' alcohol use and abuse rather than family social support [33]. Nevertheless, parental support is seen as a more effective influence on the adolescent's health behaviors. Studies also revealed controversial findings that related social support to physical and psychological well being, in general, and alcohol abuse and use, in specific. Few of the comparative longitudinal studies have the potential to yield more valid and reliable results regarding the association between substance use and social support [33]. Most of these studies focused on adolescents' use and abuse of alcohol and other drugs. They neglected the abstinence and the role of social support in adolescents' abstinence. Even those studies that reported the role of social support concepts in adolescents' use and abuse of alcohol, there was no mention of whether or not social support affected adolescents' abstinence or sobriety.

Most of the studies that discussed the effects of media on adolescents' alcohol use and abuse were conducted in the late 1980s or early 1990s. The researchers dealt with the technologies that were available at that time. The major concern now is the great advancement in the media and the time that people, in general, and adolescents, in particular, spend with the media. The great advancement in technology creates new concerns about the potential of increased social isolation and limited understanding of social relationships and human interactions. What scientists need to do now is look at the ways harmful effects of the media can be prevented. More preventive approaches should be examined for their effectiveness especially when these programs are directed toward adolescents [34]. This requires paying close attention to family relations. As mentioned in previous sections, the family and peer relationships have a direct impact on the adolescent's alcohol problems.

Peer and parental influences may function together to impact social context of adolescents and influence their choices of friends and community-based activities. A study conducted on 4230 adolescents at their 7 th to 12 th grades found that parental drug attitudes and risk of adolescents' alcohol use has been mediated by peer drug use [35]. On the other hand, parental support was found to buffer females' adolescents' alcohol use under effects of peer group affiliation [36]-[39]. However, number of studies had reported that a difference in age represented by school grades and adolescence stages appeared to be a key predictor in adolescent alcohol use [8]-[10]. Adolescents in different age groups and developmental stages appeared to be significantly different in alcohol use and alcohol use levels.

Academic achievement is been reported in regards to alcohol use among adolescents' alcohol use. It has been found that difference in alcohol use and alcohol use levels among those who reported failing grades and bad report cards and those who did not [10]. Aertgeerts and Buntinx [40] found that school performance has a significant effect on problem drinking among adolescents in grade 7 through 9. Poor academic achievements and poor grade reports had been also predicted alcohol misuse among adolescents [41] [42]. The review of the literature shows that the relationship between academic performance and alcohol consumption among adolescents is not well established. However, this study supports the negative association. 


\section{Implication and Future Direction}

The literature provides a considerable number of studies where adolescents, social support, and alcoholism are the main topics of discussion and investigation. Although the literature failed to establish a strong relationship among these three variables, the direction for future research should be directed toward using social support as a preventive approach [43]. Longitudinal-interventional social support studies are needed to strengthen the claims behind the role of social support in preventing adolescents' alcohol use and abuse [44] [45]. Moreover, now is the time to enhance the role of social support as an important factor in alcohol abstinence. Few studies have compared the effects of ecological factors such as school and neighborhood on adolescents' alcoholism. Again, more focus on alcohol education programs that are socially directed and that recognize the role of peer and school norms in adolescents' alcoholism is needed.

The few studies that discussed the role of media and public control on alcohol use and abuse among adolescents calls for more monitored applications of laws and regulation at the different levels of institution especially those who have a high percentage of adolescents such as universities and colleges. On the other hand, parents are challenged to monitor the adolescents' use of media and to foster the positive aspects of the media that are directed toward health behaviors. It is important to prevent adolescents from spending too much time on media that may shape their personalities in a negative way and serve as an obstacle to adolescents interacting and socializing in a healthy way.

\section{Conclusion}

Adolescents' alcohol use and abuse has gained a national recognition. In order to have an effective control on adolescents' use and abuse of alcohol, we need to be aware to the contributing factors. This paper provides a critical discussion of research that addresses an important factor in adolescents' alcoholism which is social support. The paper presented research findings and results of the support association and relationship between social support systems and use and abuse of alcohol among adolescents. In addition, alcohol problems among adolescents have been discussed for their significance and consequences. Family, peers, school and media have been addressed as societal systems that interfere and predict adolescents' alcohol use and abuse. The relationship of each one of these systems has been addressed and compared. Controversial findings were also discussed in terms of their effect on the relationship and reasons behind this contradiction. The paper also presented a critical discussion for the findings of reviewed studies, and presented implication for future research direction.

\section{References}

[1] Johnston, L.D., O’Malley, P.M., Bachman, J.G. and Schulenberg, J.E. (2007) Monitoring the Future: National Survey Results on Adolescent Drug Use: Overview of Key Findings, 2006. National Institute on Drug Abuse, Bethesda.

[2] Hamdan-Mansour, A., Dardas, L., AbuIsbaa, M. and Nawafleh, H. (2012) Predictors of Anger among University Students in Jordan. Children and Youth Service Review, 34, 474479. http://dx.doi.org/10.1016/j.childyouth.2011.12.004 
[3] Grunbaum, J.A., Kann, L., Kinchen, S., Ross, J., Hawkins, J., Lowry, R., Harris, W.A., McManus, T., Chyen, D. and Collins, J. (2004) Youth Risk Behaviors Surveillance-United States, 2003. Journal of School Health, 78, 308-324. http://dx.doi.org/10.1111/j.1746-1561.2004.tb06620.x

[4] Hamdan-Mansour, A. and Marmash, R. (2007) Health Concerns and Risk Behaviors among University Students in Jordan. Jordan Medical Journal, 41, 80-90.

[5] Weitzma, E.R., Nelson, T.F., Lee, H. and Wechsler, H. (2004) Reducing Drinking and Related Harms in College: Evaluation of the Matter of Degree Program. American Journal of Preventive Medicine, 27, 187-196.

[6] Gullotta, T.P., Adams, G.R. and Markstrom, C.A. (2000) The Adolescent Experience. Academic Press, San Diego.

[7] Hamdan-Mansour, A. and Dawani, H. (2009) Jordanian Nurses' Perception of Leadership Characteristics: Descriptive Phenomenological Study. Journal Medical Journal, 42, 21-32.

[8] National Institute on Drug Abuse (2003) Preventing Drug Abuse among Children and Adolescents. MD7 National Institutes of Health, Bethesda.

[9] Al Halabi, J. and Hamdan-Mansour, A. (2012) Attitudes of Jordanian Nursing Students towards Nursing Research. Journal of Research in Nursing, 17, 363-373. http://dx.doi.org/10.1177/1744987110379782

[10] Hamdan-Mansour, A., Puskar, K. and Sereika, S. (2007) Perceived Social Support, Coping Strategies and Alcohol Use among Rural Adolescents/USA Sample. International Journal of Mental Health and Addiction, 5, 53-64. http://dx.doi.org/10.1007/s11469-006-9051-7

[11] Kitzrow, M. (2003) The Mental Health Needs of Today's College Students: Challenges and Recommendations. National Association for Studies in Personality Administration, 41, 167-181.

[12] Cohen, S., Underwood, L.G. and Gottlieb, B.H. (2000) Social Relationships and Health. In: Cohen, S., Underwood, L.G. and Gottlieb, B.H., Eds., Social Support Measurement and Intervention: A Guide for Health and Social Scientists, Oxford University Press, New York, 3-25. http://dx.doi.org/10.1093/med:psych/9780195126709.003.0001

[13] Barrera, M.Jr. (1986) Distinctions between Social Support Concepts, Measures, and Models. American Journal of Community Psychology, 14, 413-445. http://dx.doi.org/10.1007/BF00922627

[14] Almadi, T., Cathers, I., Hamdan-Mansour, A. and Chow, C.M. (2012) The Association between Work Stress and Inflammatory Biomarkers in Jordanian Male Workers. Psychophysiology, 49, 172-177. http://dx.doi.org/10.1111/j.1469-8986.2011.01296.x

[15] Bandura, A. (1997) Social Learning Theory. International Nursing Review, 58, 443-449.

[16] Durkheim, E. (1951) Suicide. Free Press, New York.

[17] Arabiat, D., ALqaissi, N. and Hamdan-Mansour, A. (2011) Children's Knowledge of Their Cancer Diagnosis and Treatment: Jordanian Mothers' Perceptions and Satisfaction with the Process. International Nursing Review, 58, 443-449. http://dx.doi.org/10.1111/j.1466-7657.2011.00899.x

[18] Haegerich, T.M. and Tolan, P.H. (2008) Core Competencies and the Prevention of Adolescent Substance Use. New Directions for Child and Adolescent Development, 122, 47-60. http://dx.doi.org/10.1002/cd.228

[19] Cohen, S. and Wills, T.A. (1985) Stress, Social Support, and the Buffering Hypothesis. Psychological Bulletin, 98, 310-357. http://dx.doi.org/10.1037/0033-2909.98.2.310

[20] Hamdan-Mansour, A., Bandak, A. and Puskar, K. (2009) Effectiveness of Cognitive-Behavioral Intervention on Depressive Symptomatology, Stress and Coping Strategies among 
University Students in Jordan. Issues in Mental Health Nursing, 30, 188-196.

http://dx.doi.org/10.1080/01612840802694577

[21] Villani, S. (2001) Impact of Media on Children and Adolescents: A 10-Year Review of the Research. Journal of the American Academy of Child \& Adolescent Psychiatry, 40, 392-401. http://dx.doi.org/10.1097/00004583-200104000-00007

[22] Resnick, M.D., Bearman, P.S. and Bluam, R.W. (1997) Protecting Adolescents from Harm: Finding from the National Longitudinal Study on Adolescent Health. Journal of American Medical Association, 178, 823-832. http://dx.doi.org/10.1001/jama.1997.03550100049038

[23] Piko, B. (2000) Perceived Social Support from Parents and Peers: Which Is the Stronger Predictor of Adolescent Substance Use? Substance Use \& Misuse, 35, 617-630. http://dx.doi.org/10.3109/10826080009147475

[24] Strasburger, V.C. (2002) Alcohol Advertising and Adolescents. Pediatric Clinics of North America, 49, 353-376. http://dx.doi.org/10.1016/S0031-3955(01)00009-8

[25] Andrews, J.A., Tildesley, E., Hops, H. and Li, F. (2002) The Influence of Peers on Young Adult Substance Use. Health Psychology, 21, 349-357. http://dx.doi.org/10.1037/0278-6133.21.4.349

[26] Hussong, A.M. (2002) Differentiating Peer Contexts and Risk for Adolescent Substance Use. Journal of Youth and Adolescence, 31, 207-220. http://dx.doi.org/10.1023/A:1015085203097

[27] Hamdan-Mansour, A. (2010) Predictors of Hostility among University Students in Jordan. Scandinavian Journal of Caring Sciences, 24, 125-130. http://dx.doi.org/10.1111/j.1471-6712.2009.00695.x

[28] Hamdan-Mansour, A., Constantino, R., Farrell, M., Doswell, W., Gallagher, M.E., Safadi, R., Shishani, K. and Banimustafa, R. (2011) Evaluating the Mental Health of Jordanian Women in Intimate Partner Abuse. Issues in Mental Health Nursing, 32, 614-623. http://dx.doi.org/10.3109/01612840.2011.580494

[29] Attallah, M., Hamdan-Mansour, A., Al-Sayyed, M. and Aboshaiqa, A. (2013) Patient Satisfaction with Quality of Nursing Care Provided at Saudi Arabia. International Journal of Nursing Practice, 19, 584-590. http://dx.doi.org/10.1111/ijn.12102

[30] Al-Sagarat, A., Hamdan-Mansour, A., AL-Sarayreh, F. and Nawafleh, H. (2016) Prevalence of Aggressive Behaviors among Inpatients with Psychiatric Disorder: A Case Study Analysis from Jordan. Nursing and Health Sciences, 18, 172-179. http://dx.doi.org/10.1111/nhs.12239

[31] Leatherdale, S.T., Cameron, R., Brown, K.S., Jolin, M.A. and Kroeker, C. (2006) The Influence of Friends, Family, and Older Peers on Smoking among Elementary School Students: Low-Risk Students in High-Risk Schools. Preventive Medicine, 42, 218-222. http://dx.doi.org/10.1016/j.ypmed.2005.11.019

[32] Hoffman, B.R., Monge, P.R., Chou, C.P. and Valente, T.W. (2007) Perceived Peer Influence and Peer Selection on Adolescent Smoking. Addictive Behaviors, 32, 1546-1554. http://dx.doi.org/10.1016/j.addbeh.2006.11.016

[33] Livaudais, J.C., Napoles-Springer, A., Stewart, S. and Kaplan, C.P. (2007) Understanding Latino Adolescent Risk Behaviors: Parental and Peer Influences. Ethnicity \& Disease, 17, 298-304.

[34] Robinson, L.A., Dalton, W.T. and Nicholson, L.M. (2006) Changes in Adolescents' Sources of Cigarettes. Journal of Adolescent Health, 39, 861-867. http://dx.doi.org/10.1016/j.jadohealth.2006.06.004

[35] Mundt, M.P., Mercken, L. and Zakletskaia, L. (2012) Peer Selection and Influence Effects on 
Adolescent Alcohol Use: A Stochastic Actor-Based Model. BMC Pediatrics, 12, 115. http://dx.doi.org/10.1186/1471-2431-12-115

[36] Mathys, C., Burk, W.J. and Cillessen, A.H.N. (2013) Popularity as Moderator of Peer Selection and Socialization of Adolescent Alcohol, Marijuana, and Tobacco Use. Journal of Research on Adolescence, 23, 513-523. http://dx.doi.org/10.1111/jora.12031

[37] Al Abaiat, D., Hamdan-Mansour, A., Hanouneh, S. and Ghannam, B. (2016) Psychosocial Predictors of Relapse among Alcohol Dependents in Jordan. Current Drug Abuse Reviews, 9, 19-25. http://dx.doi.org/10.2174/187447370901160318153019

[38] Hamaideh, S. and Hamdan-Mansour, A. (2014) Psychological, Cognitive, and Personal Variables that Predict College Academic Achievement among Health Sciences Students. Nurse Education Today, 34, 703-708. http://dx.doi.org/10.1016/j.nedt.2013.09.010

[39] Hamdan-Mansour, A., Kim, Y., Puskar, K. and Amre, H. (2008) Psychometric Properties of Coping Response Inventory-Youth Form. Issues in Mental Health Nursing, 29, 371-385. http://dx.doi.org/10.1080/01612840801904423

[40] Aertgeerts, B. and Buntinx, F. (2002) The Relation between Alcohol Abuse or Dependence and Academic Performance in First-Year College Students. Journal of Adolescent Health, 31, 223-225. http://dx.doi.org/10.1016/S1054-139X(02)00362-2

[41] Laukkanen, E.R., Shemeikka, S.L., Viinamaki, H.T., Polkki, P.L. and Lehtonen, J.O. (2001) Heavy Drinking Is Associated with More Severe Psychosocial Dysfunction among Girls than Boys in Finland. Journal of Adolescent Health, 28, 270-277. http://dx.doi.org/10.1016/S1054-139X(00)00183-X

[42] Ellickson, S.L., Tucker, J.S., Klein, D.J. and McGuigan, K.A. (2001) Prospective Risk Factors for Alcohol Misuse in Late Adolescence. Journal of Studies on Alcohol, 62, 773-782. http://dx.doi.org/10.15288/jsa.2001.62.773

[43] Hamdan-Mansour, A., Ghannam, B., Al Abeiat, D., Al Badawi, T., Thulthian, I. and Shamali, I. (2014) Predicting Depression among Jordanian Patients Diagnosed with Physical Illnesses. Psychology, 5, 2120-2130. http://dx.doi.org/10.4236/psych.2014.519214

[44] Hamdan-Mansour, A. and Wardam, L. (2009) Attitudes of Jordanian Mental Health Nurses toward Mental Health Illness and Patients with Mental Illness. Issues in Mental Health Nursing, 30, 705-711. http://dx.doi.org/10.1080/01612840903131792

[45] Engels Rutger, C.M.E. and van der Vorst, H. (2003) The Roles of Parents in Adolescent and Peer Alcohol Consumption. The Netherlands Journal of Sociology, 39, 53-68. 
Submit or recommend next manuscript to SCIRP and we will provide best service for you:

Accepting pre-submission inquiries through Email, Facebook, LinkedIn, Twitter, etc. A wide selection of journals (inclusive of 9 subjects, more than 200 journals)

Providing 24-hour high-quality service

User-friendly online submission system

Fair and swift peer-review system

Efficient typesetting and proofreading procedure

Display of the result of downloads and visits, as well as the number of cited articles

Maximum dissemination of your research work

Submit your manuscript at: http://papersubmission.scirp.org/ 